\title{
Non-Newtonian flow characterization of heavy crude oil in porous media
}

\author{
Xiaohu Dong · Huiqing Liu • Qing Wang • \\ Zhanxi Pang $\cdot$ Changjiu Wang
}

Received: 25 May 2012/ Accepted: 5 November 2012/Published online: 22 November 2012

(C) The Author(s) 2012. This article is published with open access at Springerlink.com

\begin{abstract}
As a temperature-sensitive non-Newtonian fluid, the seepage of heavy crude oil in porous media shows the non-linear characteristics. The flowing behavior of three heavy oils through porous media is experimentally investigated, and the influence of temperature and pressure-drop on this flowing process is also described. Thereafter, based on the flowing behavior of heavy crude oil, the new models of productivity of the thermal producers (including vertical well and horizontal well) are proposed. In these models, both the threshold pressure gradient (TPG) and thermal effect are taken into account. The flowing experiments of heavy oil in porous media indicate that the pressure gradient and temperature have the significant influence on the flowing process because of the existence of threshold temperature and TPG. Heavy crude oil begins to flow only when the pressure gradient is in excess of TPG, and there dose not actually exist TPG above the threshold temperature. The viscosity-temperature curves demonstrate that the viscosity of heavy crude oil has an obvious feature of two straight-lines on semilog coordinate. On account of the damage of overlapping phenomena of asphaltenes in crude oil, when temperature is higher than the critical temperature, the reducing trend of TPG (with the increase of temperature) will be lessened. Furthermore, on the basis of flowing process of heavy crude oil, the concepts of threshold temperature and certain production temperature of thermal wells are introduced. That heavy oil with a higher viscosity would have a higher threshold temperature, as well as the certain production temperature. The application of horizontal wells
\end{abstract}

X. Dong $(\varangle) \cdot$ H. Liu $\cdot$ Q. Wang $\cdot$ Z. Pang $\cdot$ C. Wang MOE Key Laboratory of Petroleum Engineering, China University of Petroleum, No. 18 Fuxue Road, Changping District, Beijing 102249, People's Republic of China e-mail: donghu820@163.com tremendously increases the oil recovery rate in comparison with the vertical wells. This investigation could be used as a tool to study the flowing process of heavy oil and productivity calculation of thermal wells in heavy oil reservoirs.

Keywords Heavy crude oil · Porous media - Bingham model . Flow characterization · Productivity analysis

\section{Introduction}

The increasing energy demand is leading to the development of the very large world resources of heavy crude oils that are of the same order of magnitude than conventional oils. However, the production and transport of these oils are challenging because of their non-Newtonian flow characterization in reservoir. The rheology of heavy crude oil plays an important role in the flowing process of oil through porous media, and the rheological behavior of heavy crude oil is directly related to the development indexes, like well productivity and oil recovery (Chen and Lu 1990; Henaut 2003; Prada and Civan 1999). High viscosity and high density are the most prominent properties of heavy crude oil, resulting in a major difference of rheology feature with the conventional oil. Under the reservoir condition, the flow of heavy oil through porous media is a non-linear seepage process. That makes it difficult for heavy oil to flow. In other words, the development of heavy oil reservoirs must meet two conditions: (1) oil could flow into the well bottom from reservoir; (2) oil could be lifted into the ground from well bottom continuously (Chen and Lu 1990; Alshmakhy and Maini 2011). Therefore, changing the rheology properties in reservoir or in wellbore has become an essential work in order to improve the flowing ability of heavy oil and achieve a sustainable production. 
Due to a large domain of applications, a number of experimental and theoretical studies have been concerned with the flow characterization for heavy crude oil flow through porous media. Traditionally, the studies of flow characterization and rheology of heavy crude oil mainly concentrate on the following three aspects. First, the composition of heavy oils, particularly the content of asphaltenes and resins, plays an important role for the flowing process of heavy crude oil, it is the leading cause of their high viscosity (Argillier et al. 2002; Schramm and Kwak 1988; Ovalles et al. 2011; Steinborn and Flock 1983). Henaut et al. (2003) and Argillier et al. (2002) investigated the influence of asphaltenes and resins content on oil viscosity. Their experimental work revealed the existence of a critical concentration above which the asphaltenes particles overlap. This structural change dramatically increases the oil viscosity and intensifies the elastic character of heavy crude oil. It has been demonstrated that without resins, the viscosity would be even higher. By removing the asphaltenes from heavy oils, a reduction of 2-3 order of magnitude on the viscosity will be observed over all the temperature range (Schramm and Kwak 1988; Ovalles et al. 2011). Generally, the viscosity of heavy crude oil could be reduced by the use of additive that can act as the modifiers of aggregation behavior of asphaltenes (Ovalles et al. 2011). Second, the rheological property of heavy oil is closely related to the reservoir temperature. Heavy crude oil has a viscoelastic property while the temperature is low and behaves as a Newtonian fluid while temperature increases (Wang et al. 2006; Chen et al. 2005). The Bingham model is used to describe the flowing process of heavy oil in porous media by many researchers (Wu et al. 1992; Thomas et al. 1967; Pruess and Zhang 1990). For Bingham fluid, heavy oil would not flow when stress is below the yield, and it would present the flowing characteristics of Newtonian fluid above the yield stress. The major difference between Bingham fluid and heavy oil is that the viscosity of heavy oil is dependent on temperature, and heavy oil is a temperature-sensitive Bingham fluid. Thomas et al. (1967), Pruess and Zhang (1990) and Song et al. (2001) studied the threshold pressure gradient (TPG) of heavy crude oil in porous media. The third, many studies also indicated that the heavy crude oil is a thixotropic fluid with the shear shinning property (Wang et al. 2006; Govier and Fogurasi 1972; Rojas et al. 2008; Christos 2004). Wang et al. (2006) investigated the flowing characteristics and rheology of Zaoyuan heavy oil. Their results show that the Zaoyuan heavy oil has a TPG and a thixotropic property in porous media. The shear stress of this oil decreases with the shear time. Rojas et al. (2008) proposed an expression combining the Power-Law model, Arrhenius equation, and the liquid crystal theory. It is used to explain not only the shear thinning phenomenon but also to estimate effectively complex viscosity in terms of frequency and temperature.

Moreover, the temperature-sensitivity of TPG of heavy crude oil should be taken into consideration. During the flowing process of heavy oil in porous media, it is necessary to raise the temperature for shifting the flow-state from nonNewtonian viscoelastic fluid to Newtonian fluid. This fluid transformation temperature is defined as the critical temperature. Therefore, the temperature of reservoir and wellbore should be kept above the critical temperature to exploit. Different type of heavy oil reservoir has different critical temperature. The determination of critical temperature plays an important role in the exploitation of heavy oil reservoirs.

The investigation in this study is concerned with the flowing process of heavy crude oil in porous media. Using the steady-state method, the relationship between displacement pressure-drop and flow rate is experimentally investigated in this paper. From the data generated in this process, the influence of oil viscosity, reservoir permeability and temperature on flow characterization of heavy crude oil is discussed. Also, the TPG and critical temperature of heavy oil is obtained.

Based on the seepage experiments of heavy crude oil in porous media, a new predictive model of thermal-wellproductivity (including vertical well and horizontal well) is also investigated. In this model, both the TPG and thermal effect of heavy crude oil are taken into consideration. From the calculation results of this model, we could obtain the threshold temperature and the certain-production temperature of thermal wells.

\section{Experimental setup and procedure}

\section{Equipment and operation}

The flowing experiments were carried out by injecting oil into sand-packed cores using a constant infusion pump (ISCO pump), as shown in Fig. 1. This sand pack was fabricated from the standard, type-316 stainless-steel tubing and fitting, and had a $2.5-\mathrm{cm}$ inside diameter and $35-\mathrm{cm}$ length. The flow rate of this pump ranges from $10^{-5}$ to $50 \mathrm{~cm}^{3} / \mathrm{min}$. The pressure-drop between inlet-end and outlet-end of the cores was measured by a pressure sensor (absolute precision: $0.01 \mathrm{kPa}$ ) and recorded by a digital recorder. Before the flowing experiments, a Brookfield rotational viscometer is used for the oil viscosity measurement. In this study, about nine flowing experiments (three oils at three different permeability conditions) were performed.

Steady-state method was the most commonly employed as the test method of flowing characteristics. It had the great advantages of reliable data and high precision, although it was quite time-consuming. The experiments were carried 


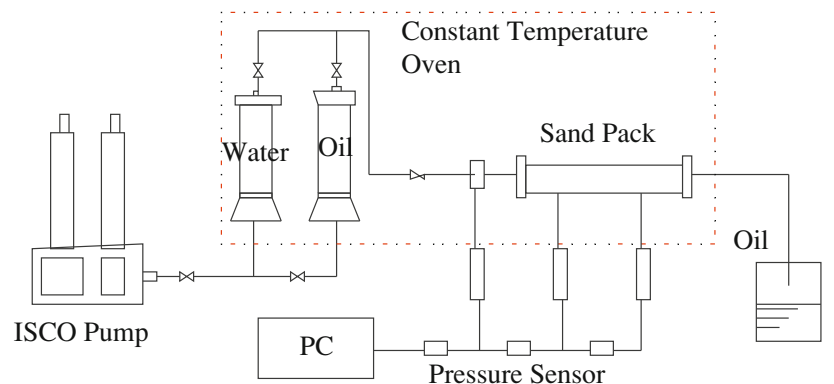

Fig. 1 A schematic drawing of the flowing experiment apparatus

out as described in the following. An artificially prepared sand-packed core sample was vacuumed prior to running experiments. Then, the core sample is saturated with distilled water. From the relationship of flow rate and pressure-drop measured in this process, the porosity and permeability of the core sample could be obtained. Afterwards, the oil injection process is performed to establish the oil saturation field at irreducible water condition. During this process, the furnace temperature is adjusted to the desired experimental temperature. When the heavy oil injected reaches $2-3$ pore volumes, it could be supposed that the single-phase flow process of heavy oil has been achieved. Then, the flow test is started. The injection flow rate of the infusion pump is adjusted gradually from a small value to the desired higher value. At each flow rate, the pressure differences across the core sample are measured after a steady flow condition is attained. The adequate equilibrium time $(5-10 \mathrm{~h})$ should be guaranteed to assure the precision of measurement.

\section{Material}

The heavy oil samples used in the experiments were the dead oils obtained from three thermal horizontal wells in Karamay oilfield, denoted as Well \#13161, 13121, and 13041. Before operation, these three oil samples were filtered with a stainless steel meshes (pore diameter: $0.045 \mathrm{~mm}$ ) below the temperature of $80{ }^{\circ} \mathrm{C}$ to remove the sandstone and mechanical impurities. After that, an automatic crude oil dehydrating device is used for the oil dehydrating. Sand is the quartz sand with uniform grain size and good abrasion (80mesh, 120-mesh, and 160-mesh). This sand has a good thermostabilization, and there is no chemical reactions occurred within $400{ }^{\circ} \mathrm{C}$. The processed oils were used for component analysis, viscosity-temperature measurement and rheological behavior measurement.

\section{Flow characterization of heavy oil}

Currently, the experiments of heavy crude oil through capillary tube and porous media are the most commonly

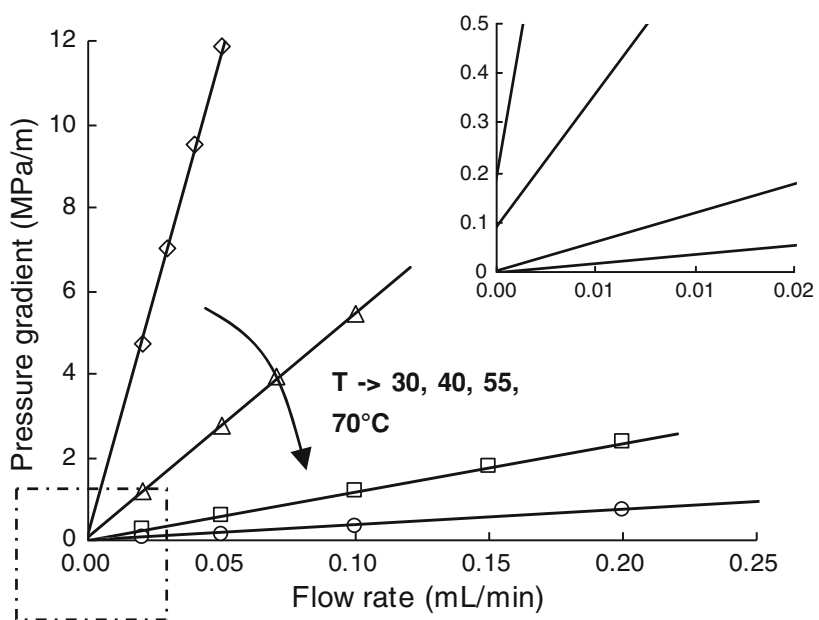

Fig. 2 Heavy oil flow through porous media-Well 13161, $K=9,180 \times 10^{-3} \mu \mathrm{m}^{2}$

used as the test experiments of flow characterization. The former is based on the assumption of capillary tube bundles. In capillary tube models, the reservoir rock is supposed as a pore space with multi capillary tube, and it is an ideal flowing process. Thus, the flowing experiments of heavy oil in porous media offer a genuine opportunity for the flow process in reservoir.

Flowing experiments of these three oil samples were performed in porous media under the different permeability conditions. Figures 2, 3, 4, 5, 6, 7, 8, 9, 10 and 11 present the experimental data and the results of fitting model. As shown, the pressure gradient increases with the rise of flow rate, which approximately keeps a linear relationship. The experimental results have been correlated by regression with a linear equation. From these straight lines, the TPG of heavy crude oil under different flowing conditions could be determined.

Figures 2, 3 and 4 present the flowing experiment results of oil \#13161. As shown, for a given permeability, with the increase of flow rate, the pressure gradient of core shows an increasing-trend. With the rise of furnace temperature, both the oil viscosity and the pressure-drop will be decreased. From Fig. 2, it is indicated that the TPG of heavy oil $\# 13161$ at the temperature of 30 and $55^{\circ} \mathrm{C}$ are 0.202 and $0.002 \mathrm{MPa} / \mathrm{m}$, respectively (the intercept of the corresponding straight line). While the temperature increased to $70{ }^{\circ} \mathrm{C}$, the TPG of this oil will fall to zero. By the method of linear interpolation, we get the temperature breakpoint of this oil is about $58{ }^{\circ} \mathrm{C}$. When the permeability of porous media is reduced to the mid-permeability condition $\left(K=3,660 \times 10^{-3} \mu \mathrm{m}^{2}\right)$, the TPG of this oil at the temperature of $30{ }^{\circ} \mathrm{C}$ has increased to $0.784 \mathrm{MPa} / \mathrm{m}$, about 3-4 times than the high-permeability condition. It falls to zero at $80^{\circ} \mathrm{C}$, and also we could obtain that the temperature breakpoint of this oil at mid-permeability condition is about 


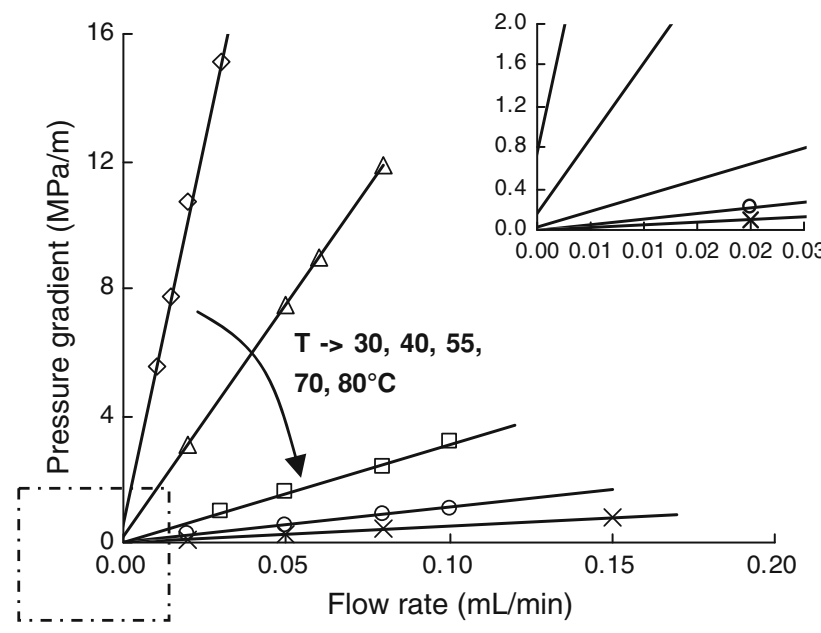

Fig. 3 Heavy oil flow through porous media-Well 13161, $K=3,660 \times 10^{-3} \mu \mathrm{m}^{2}$

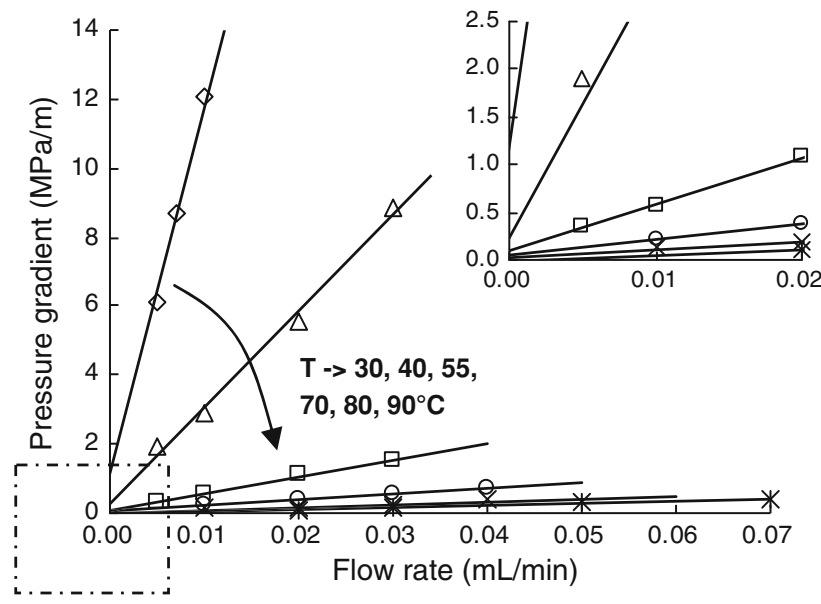

Fig. 4 Heavy oil flow through porous media-Well 13161, $K=1,320 \times 10^{-3} \mu \mathrm{m}^{2}$

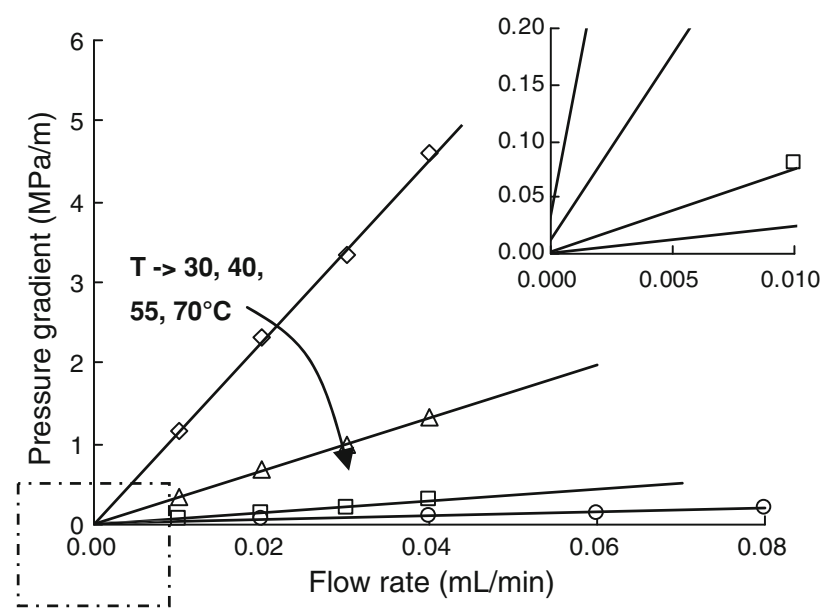

Fig. 5 Heavy oil flow through porous media-Well 13121, $K=9,180 \times 10^{-3} \mu \mathrm{m}^{2}$
$72{ }^{\circ} \mathrm{C}$. In a similar way, it is calculated the temperature breakpoint at low-permeability $\left(K=1,320 \times 10^{-3} \mu \mathrm{m}^{2}\right)$ condition is about $85^{\circ} \mathrm{C}$.

The flow characterization of oil \#13121 and 13041 is shown in Figs. 5, 6, 7, 8, 9 and 10. Analogously, from these figures, the TPGs of these two oils at different temperature and the temperature breakpoints can be obtained. For oil \#13121, the temperature breakpoints at these three permeability conditions are 57,65 and $82^{\circ} \mathrm{C}$, respectively. From the test results of oil \#13041 (Figs. 8, 9, 10), it is indicated that the TPG of this oil at the high-permeability condition does not exist, and it do not exist the temperature breakpoint. Inversely, the temperature breakpoints of

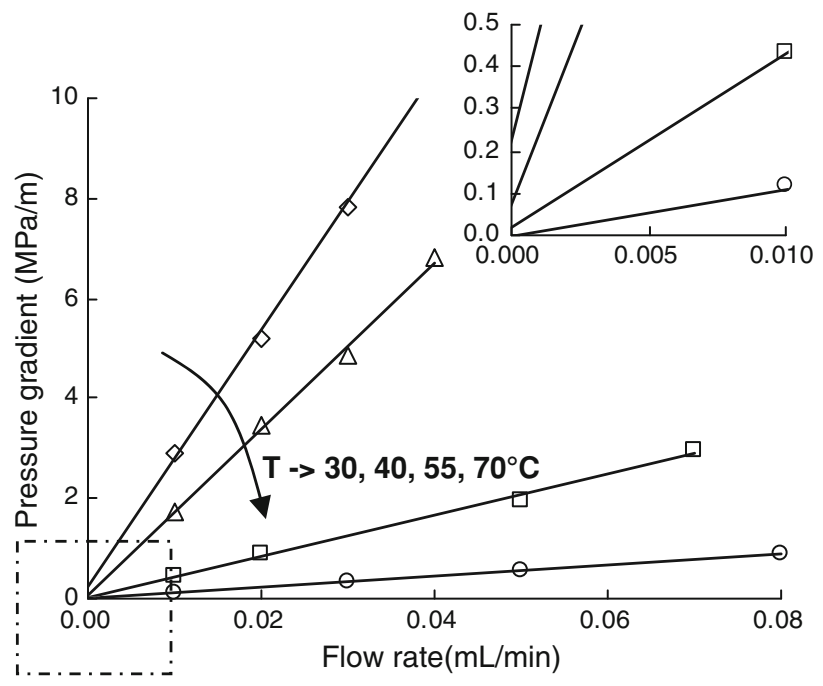

Fig. 6 Heavy oil flow through porous media-Well 13121, $\mathrm{K}=3,660 \times 10^{-3} \mu^{2}$

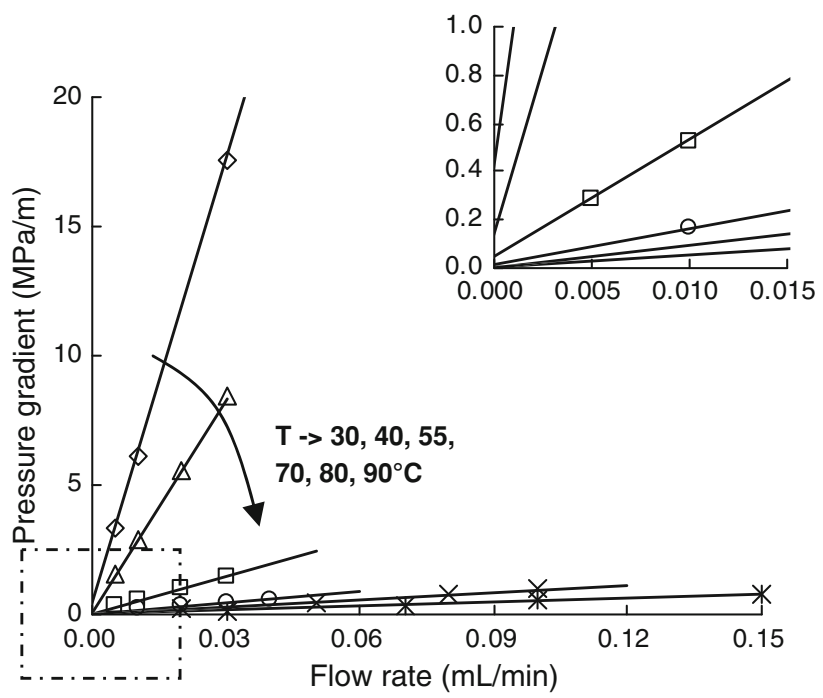

Fig. 7 Heavy oil flow through porous media-Well 13121, $K=1,320 \times 10^{-3} \mu \mathrm{m}^{2}$ 


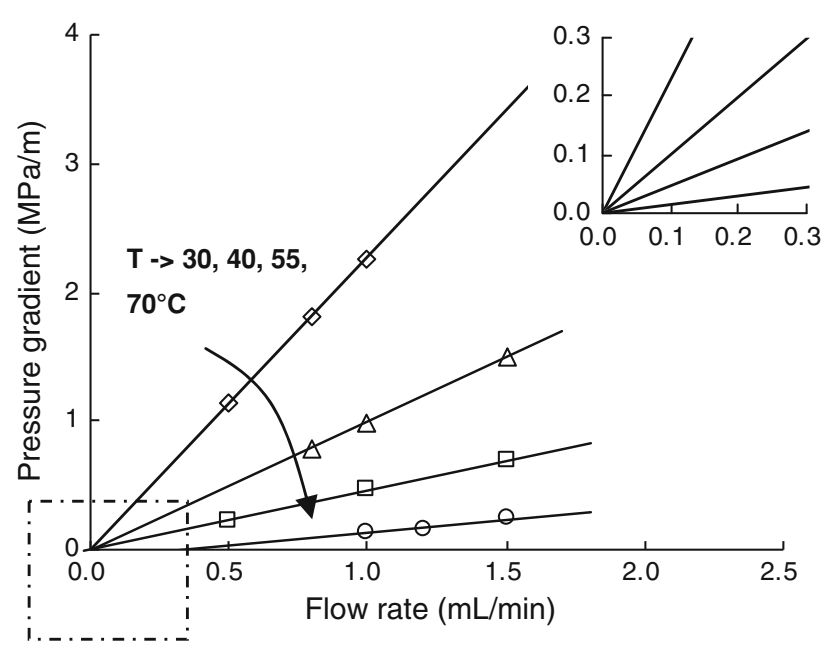

Fig. 8 Heavy oil flow through porous media-Well 13041, $K=9,180 \times 10^{-3} \mu \mathrm{m}^{2}$

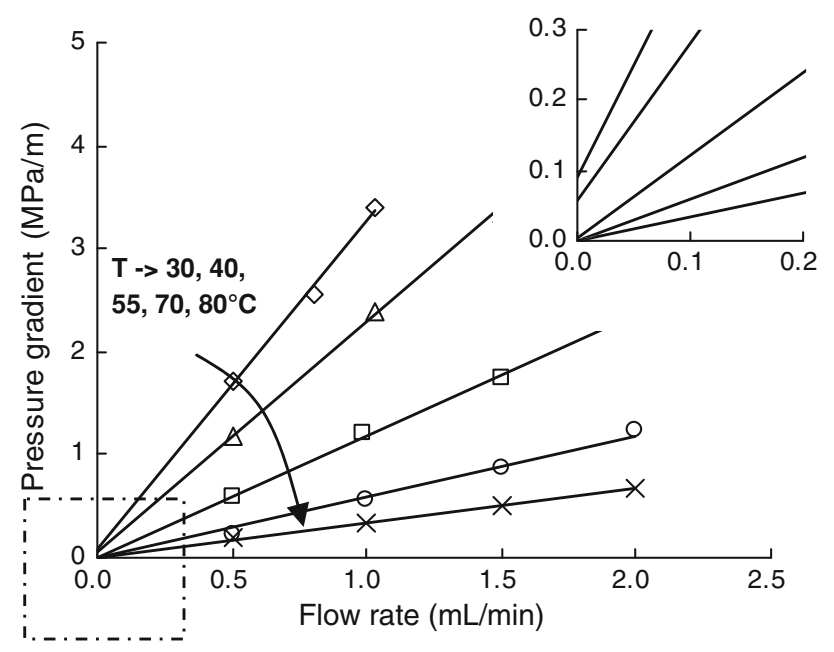

Fig. 9 Heavy oil flow through porous media-Well 13041, $K=3,660 \times 10^{-3} \mu \mathrm{m}^{2}$

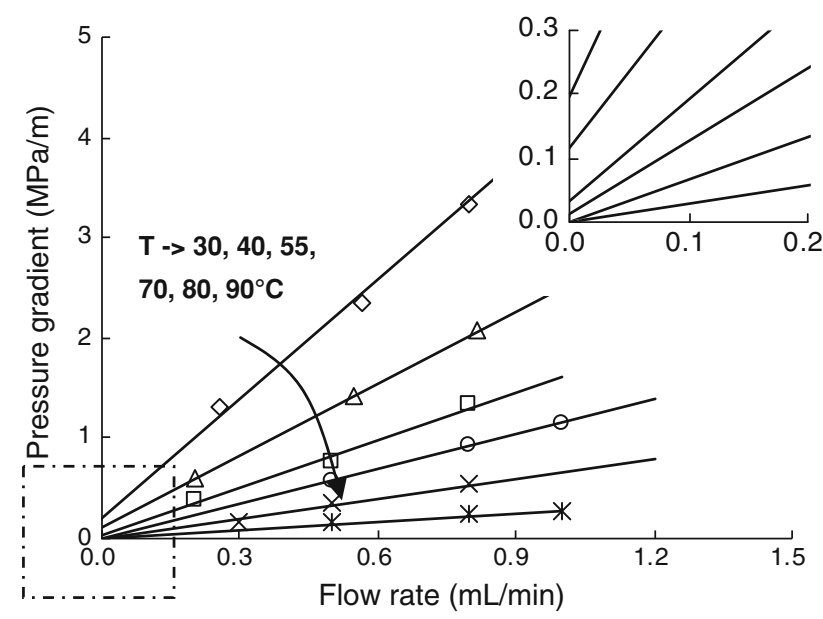

Fig. 10 Heavy oil flow through porous media-Well 13041, $K=1,320 \times 10^{-3} \mu \mathrm{m}^{2}$

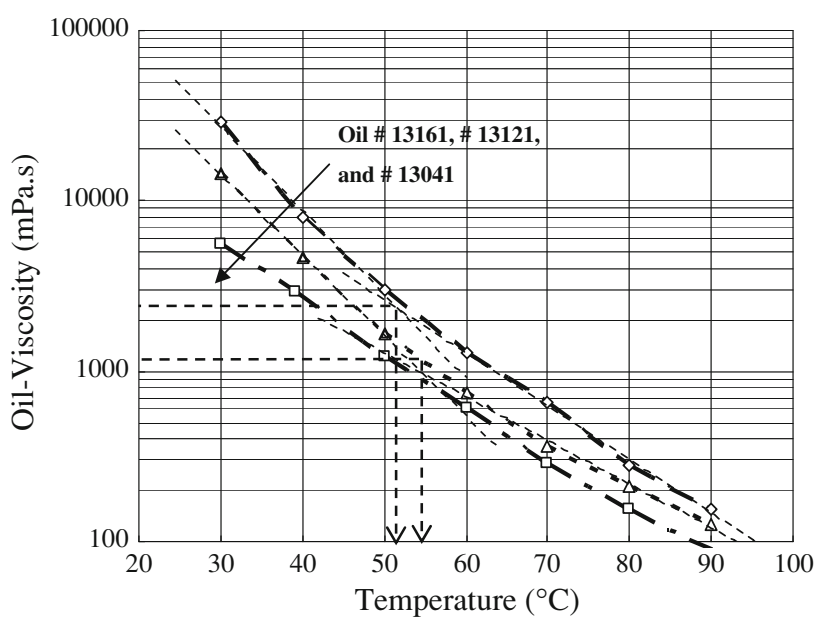

Fig. 11 Viscosity-temperature curves of these three heavy crude oils

mid- and low-permeability conditions are 57 and $72{ }^{\circ} \mathrm{C}$, respectively.

In addition, uncertainty evaluation is a crucial part for the linear regression. Therefore, the uncertainties of slope $(a)$ and intercept $(b)$ of this linear regression are estimated according to the formulas below:

$s_{x y}=\sqrt{\frac{\sum v_{i}^{2}}{n-2}}=\sqrt{\frac{\sum\left(y_{i}-\hat{y}\right)^{2}}{n-2}}$

$u_{(a)}=s_{(a)}=s_{x y} \sqrt{\frac{1}{n}+\frac{\bar{x}^{2}}{\sum\left(x_{i}-\bar{x}\right)^{2}}}$

$u_{(b)}=s_{(b)}=s_{x y} \sqrt{\frac{1}{\sum\left(x_{i}-\bar{x}\right)^{2}}}$

where $\left(x_{i}, y_{i}\right)$ represents the experimental data point; $\hat{y}$ is the predicted value according to the fitting equation; $i$ is the number of experimental data; $\bar{x}$ is the arithmetical mean value of the variable, $x_{i} ; u_{(a)}$ and $u_{(b)}$ are the uncertainties of the slope and intercept for the linear regression.

Table 1 presents the results of the slope and intercept for the linear regression ' $y=a x+b$ ' using the equations above. From the table, we can see the ranges of the values of slope and intercept are:

$0.006 \leq u_{(a)} \leq 0.221$

$0.008 \leq u_{(b)} \leq 3.861$

As shown, the slope uncertainty of this linear regression is significantly less than that of the intercept. In comparison with intercept, the slope is much more reliable. In addition, it is indicated that the values of $u_{(a)}$ and $u_{(b)}$ show much higher for the cases of low-temperature conditions. And with the increase of temperature, the uncertainty is reducing yet and the accuracy is increased. The average value of 
Table 1 The uncertainty results of the slope and intercept for linear regression
$K_{H}$ high-permeability cases, $K_{M}$ mid-permeability cases, $K_{L}$ lowpermeability cases

\begin{tabular}{|c|c|c|c|c|c|c|c|c|c|c|}
\hline \multicolumn{2}{|c|}{ Temperature $\left({ }^{\circ} \mathrm{C}\right)$} & \multicolumn{3}{|c|}{ Oil \#13161 } & \multicolumn{3}{|c|}{ Oil \#13121 } & \multicolumn{3}{|c|}{ Oil \#13041 } \\
\hline & & $K_{\mathrm{H}}$ & $K_{\mathrm{M}}$ & $K_{\mathrm{L}}$ & $K_{\mathrm{H}}$ & $K_{\mathrm{M}}$ & $K_{\mathrm{L}}$ & $K_{\mathrm{H}}$ & $K_{\mathrm{M}}$ & $K_{\mathrm{L}}$ \\
\hline \multirow[t]{2}{*}{30} & $u_{(a)}$ & 0.221 & 0.056 & 0.116 & 0.086 & 0.029 & 0.101 & 0.034 & 0.032 & 0.040 \\
\hline & $u_{(b)}$ & 1.868 & 1.870 & 3.841 & 3.861 & 2.260 & 1.144 & 0.030 & 0.086 & 0.245 \\
\hline \multirow[t]{2}{*}{40} & $u_{(a)}$ & 0.052 & 0.026 & 0.036 & 0.032 & 0.157 & 0.061 & 0.040 & 0.061 & 0.013 \\
\hline & $u_{(b)}$ & 0.295 & 0.600 & 1.020 & 0.949 & 0.203 & 0.151 & 0.062 & 0.055 & 0.026 \\
\hline \multirow[t]{2}{*}{55} & $u_{(a)}$ & 0.009 & 0.087 & 0.017 & 0.009 & 0.079 & 0.016 & 0.006 & 0.046 & 0.057 \\
\hline & $u_{(b)}$ & 0.087 & 0.615 & 0.889 & 0.417 & 0.668 & 0.157 & 0.008 & 0.041 & 0.128 \\
\hline \multirow[t]{2}{*}{70} & $u_{(a)}$ & 0.020 & 0.034 & 0.022 & 0.016 & 0.007 & 0.019 & 0.066 & 0.086 & 0.024 \\
\hline & $u_{(b)}$ & 0.085 & 0.154 & 0.175 & 0.376 & 0.137 & 0.166 & 0.128 & 0.077 & 0.064 \\
\hline \multirow[t]{2}{*}{80} & $u_{(a)}$ & - & 0.008 & 0.029 & - & - & 0.025 & - & 0.019 & 0.040 \\
\hline & $u_{(b)}$ & - & 0.078 & 0.328 & - & - & 0.077 & - & 0.017 & 0.108 \\
\hline \multirow[t]{2}{*}{90} & $u_{(a)}$ & - & - & 0.018 & - & - & 0.016 & - & - & 0.037 \\
\hline & $u_{(b)}$ & - & - & 0.168 & - & - & 0.146 & - & - & 0.099 \\
\hline
\end{tabular}

$u_{(a)}$ is about 0.046 , and the $u_{(b)}$ is about 0.545 . Generally, it is within the margin of error, and the accuracy is reliable.

On account of the non-Newtonian behavior of heavy oil, especially for the cases at low-temperature condition, the relation between displacement-pressure-drop and flow-rate is not a rigorous linearity. Also considering the precision limitation of experimental equipments (e.g., pressure sensor, ISCO pump), it will show a higher experimental uncertainty at the low-temperature condition. As a final result, the slope and intercept of the linear regression also show a high uncertainty. From Table 1, it is also concluded that there will present a higher uncertainty at the lowpermeability condition, in comparison with the cases of high-permeability porous media. In addition, as shown, the uncertainties of oil \#13041 are lower than that of the oil \#13161 and \#13121. That mainly results from the lower viscosity of oil \#13041 at the same temperature condition.

Figure 11 shows the viscosity-temperature curves of these three oils from the Brookfield rotational viscometer. As shown, oil \#13041 is the ordinary heavy oil of type II, and the other ones (\#13161 and \#13121) are the extra heavy oil type. It is observed that the viscosity-temperature curves of oil \#13161 and \#13121 have the obvious property of two straight lines with the different slopes on semilog coordinate. The first-line slope is much higher than that of the second line. The intersection point of these two lines is defined as the turning point of temperature. It differs from the temperature breakpoint from the flowing experiments of porous media. The turning temperatures of oil \#13161 and \#13121 are about 52 and $56{ }^{\circ} \mathrm{C}$. They are much smaller than that of the flowing experiments, which is resulted from the different rheological properties in different measuring conditions (Yang and He 2003). Traditionally, the apparent-viscosity of crude oil from the rotational viscometer is the lowest. Compared with it, the apparent-viscosity in capillary tube is a little increased, and the apparent-viscosity in porous media is the highest. For that porous media with a lower permeability, this phenomenon is much more distinct. Thus, the temperature breakpoint of heavy crude oil is also increased accordingly under a lower permeability condition. The oil rheological features in porous media (including the natural core and the sand pack) are of practical significance in the oilfield development.

Based on the results of flowing experiments, the TPG of heavy crude oil under different conditions could be obtained when the non-Newtonian flowing characteristics is taken into consideration, as shown in Figs. 12, 13 and 14. With the rise of oil viscosity, the TPG of heavy oil is increased gradually. Also the influence of temperature on crude oil with a high-viscosity is more distinct than the low-viscosity oil. For the heavy crude oil \#13161, the TPG is reduced by about $70 \%$ when the furnace temperature is increased from 30 to $40{ }^{\circ} \mathrm{C}$. However, for the oil \#13041, the TPG is only reduced about $40 \%$ when the furnace temperature is increased from 30 to $40{ }^{\circ} \mathrm{C}$.

Besides from the Figs. 12 and 13, it is indicated that there exists an obvious breakpoint of temperature for heavy oil \#13161 and \#13121, about $40{ }^{\circ} \mathrm{C}$. When the temperature is lower than $40{ }^{\circ} \mathrm{C}$, the reducing trend of TPG with the increase of temperature is much remarkable. On the contrary, when the temperature is higher than $40{ }^{\circ} \mathrm{C}$, the influence of temperature on the TPG of heavy crude oil has been weakened. This breakpoint could be explained as the critical temperature of asphaltenes. When temperature is higher than this critical temperature, the overlapping phenomena of asphaltenes in crude oil will be destroyed (Argillier et al. 2002; Ovalles et al. 2011). As shown, this breakpoint mainly depends on the oil components and is not relevant to the reservoir properties (including porosity, permeability, etc.). For the oil \#13041, there is not an 
obvious temperature breakpoint. Under the high-permeability condition $\left(K=9,180 \times 10^{-3} \mu \mathrm{m}^{2}\right)$, The TPG does not exist, but with the decrease of permeability, the TPG phenomenon of crude oil emerges gradually. With the increase of temperature, the TPG of crude oil is reduced. Therefore, the TPG of heavy crude oil is not only relevant to the reservoir properties (porosity, permeability, temperature, etc.), but also has a lot to do with the oil components.

\section{Evaluation of flowing ability for thermal producers}

Evaluation method of vertical well

Nine-spot pattern is the relatively common pattern type of steam flooding in heavy oil reservoirs. In comparison with the other well patterns, the controlling area of nine-spot

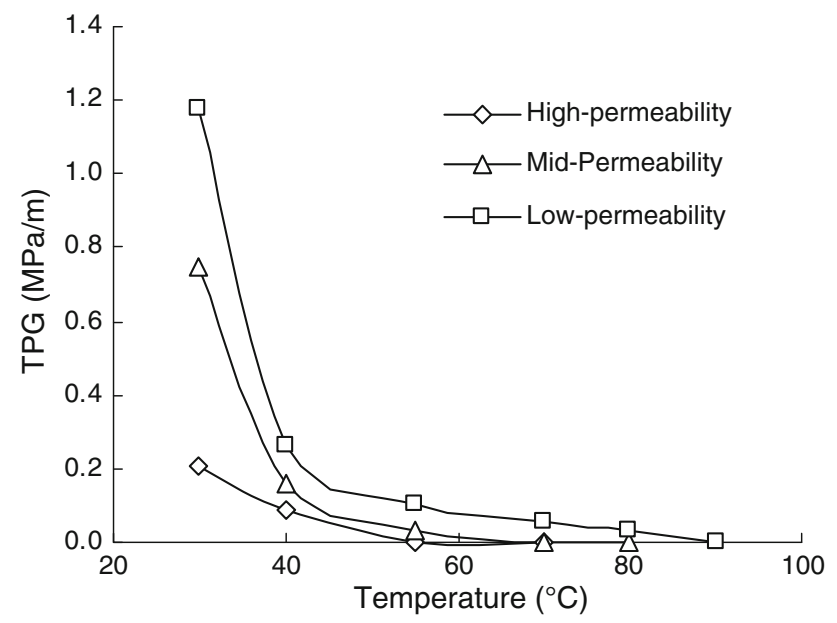

Fig. 12 TPG curves of heavy crude oil \#13161 at different temperatures

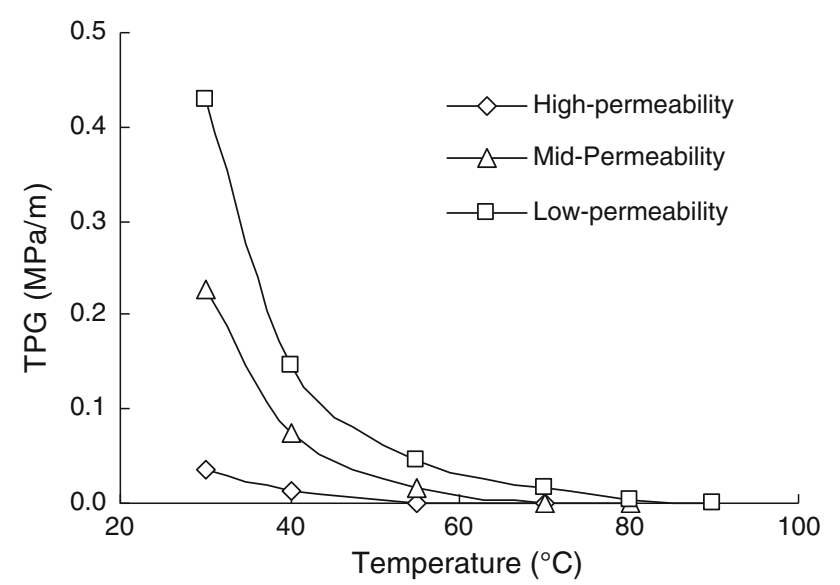

Fig. 13 TPG curves of heavy crude oil \#13121 at different temperatures pattern is much larger. As Fig. 15 shown, $L$ is the welldistance of injector and edge-well of nine-spot pattern. $S$ is the controlling area of injector, and the equivalent diameter of circular control area is $R_{\mathrm{e}}$.

From Fig. 15, the controlling area of injector in ninespot pattern appears as:

$S=(2 L)^{2}=\pi R_{\mathrm{e}}^{2}$

Therefore, the equivalent diameter of circular control area can be expressed as following:

$R_{\mathrm{e}}=2 L \sqrt{\frac{1}{\pi}}=1.1284 L$

The flowing characteristics of heavy oil show that the existence of TPG is a crucial feature of the flow of heavy crude oil through porous media and capillary tube. When pressure gradient of heavy oil is in excess of the TPG, it could resume the flowing status. The motion equation for heavy oil in porous media is given as follows:

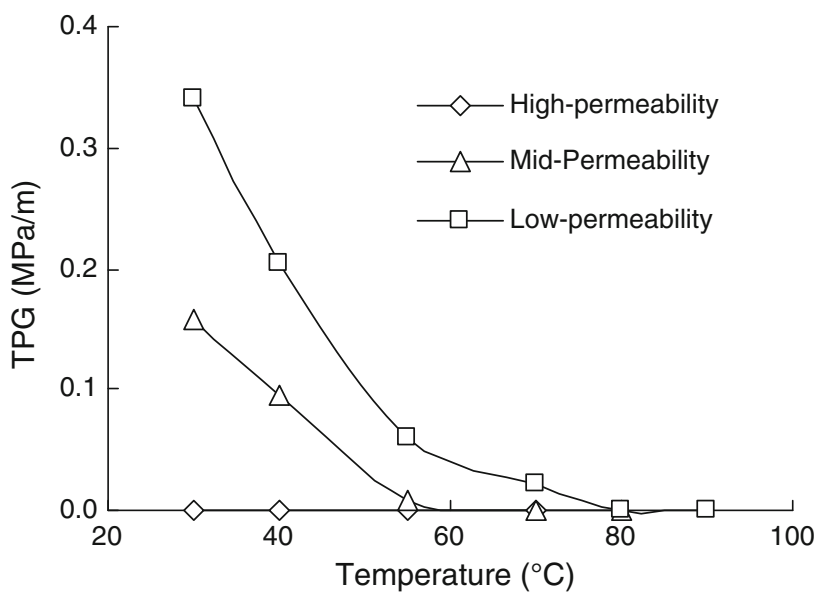

Fig. 14 TPG curves of heavy crude oil \#13041 at different temperatures

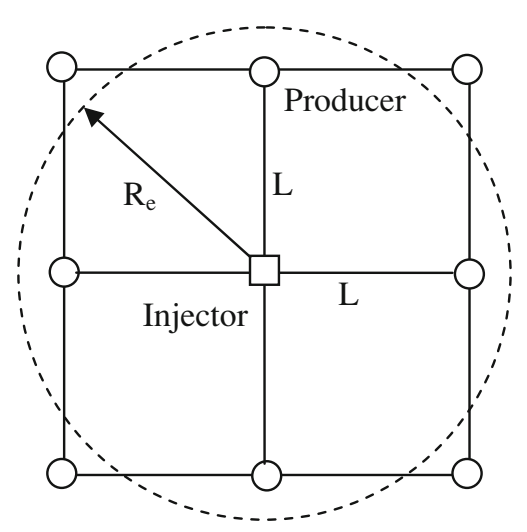

Fig. 15 A schematic drawing of the nine-spot pattern 


$$
\left\{\begin{array}{l}
\vec{v}=0 \quad \text { while } \frac{\mathrm{d} p}{\mathrm{~d} r}<\lambda, \text { and } \\
\vec{v}=-\frac{K}{\mu(T)}\left(\frac{\mathrm{d} p}{\mathrm{~d} r}-\lambda\right) \text { while } \frac{\mathrm{d} p}{\mathrm{~d} r}>\lambda
\end{array}\right.
$$

where, $K$ represents the permeability of porous media, $\lambda$ is the TPG, $\mu(T)$ is the viscosity of heavy oil. For the vertical wells, when the TPG is taken into consideration, the well productivity should be corrected as:

$\mathrm{d} Q=v A=2 \pi r h \frac{K}{\mu(T)}\left(\frac{\mathrm{d} p}{\mathrm{~d} r}-\lambda(T)\right)$

By the separate variable method, integrating the above formula, it is obtained:

$$
\begin{aligned}
Q_{\mathrm{vw}} & =\frac{2 \pi K h\left[p_{\mathrm{i}}-p_{\mathrm{w}}-\lambda(T)\left(R_{\mathrm{e}}-R_{\mathrm{w}}\right)\right]}{\mu(T) \ln \left(R_{\mathrm{e}} / R_{\mathrm{w}}\right)} \\
& =\frac{2 \pi K h\left[\Delta p-\lambda(T)\left(R_{\mathrm{e}}-R_{\mathrm{w}}\right)\right]}{\mu(T) \ln \left(R_{\mathrm{e}} / R_{\mathrm{w}}\right)}
\end{aligned}
$$

Equation (8) is the new model of vertical-well productivity, and it considers the influence of TPG and thermal effect of heavy crude oil on well productivity. This model could be used for the productivity evaluation of thermal vertical well.

Evaluation method of horizontal well

For the thin reservoirs, the application of horizontal wells is more economical and effective. The contact area of horizontal well and reservoir is larger than vertical well, and single-well productivity of horizontal well is also increased. Considering this situation, thermal horizontal well has become an important tool for the EOR of heavy oil reservoirs. Based on the assumption of elliptical drainage volume, Joshi transforms the 3D flowing of horizontal wells into 2D flowing of vertical plane and horizontal plane (Joshi 1988). The well productivity model of horizontal wells in homogeneous reservoirs is given by:

$Q_{\mathrm{hw}}=\frac{2 \pi K_{\mathrm{o}} h \Delta p}{\mu\left\{\ln \left[\frac{a+\sqrt{a^{2}-(L / 2)^{2}}}{L / 2}\right]+\frac{h}{L} \ln \left(\frac{h}{2 R_{\mathrm{w}}}\right)\right\}}$

where, $a=(L / 2)\left[1 / 2+\sqrt{1 / 4+\frac{1}{\left(0.5 L / R_{\mathrm{e}}\right)^{4}}}\right]^{0.5}$

In Eq. (9), $L / 2$ is the half-length of horizontal segment, it equals a half of the focus in elliptical drainage volume.

$L / 2=\sqrt{a^{2}-b^{2}}$

According to the relation of this circle-control-area and the ellipse-control-area, the horizontal-well drainage radius, $R_{\mathrm{e}}$, is calculated.
$R_{\mathrm{e}}=\sqrt{A / \pi}=\sqrt{a b}$

From Eq. (11) and (12), we could obtain the expression of $a$ in Eq. (9), as the Eq. (10) shown.

Joshi model could be used for the single-phase flowing process in isotropic reservoirs. For heavy oil reservoirs, the influence of TPG and thermal effect on the productivity of horizontal wells should be taken into consideration (Owayed and Tiab 2008; Wu and Pruess 1998). Therefore, the productivity model of horizontal wells in heavy oil reservoirs could be corrected by:

$Q_{\mathrm{hw}}=\frac{2 \pi K_{\mathrm{h}} h\left[\Delta p-\lambda(T)\left(R_{\mathrm{e}}-R_{\mathrm{w}}\right)\right]}{\mu(T)\left\{\ln \left[\frac{a+\sqrt{a^{2}-(L / 2)^{2}}}{L / 2}\right]+\frac{h}{L} \ln \left(\frac{h}{2 R_{\mathrm{w}}}\right)\right\}}$

Equations (8) and (13) are the new productivity models of thermal producers. This model has fully considered the influence of TPG and thermal effect on well-productivity. Therefore, when only the thermal well type is considered, the relationship between vertical-well-productivity and horizontal-well-productivity could be given by:

$\delta=\frac{Q_{\mathrm{hw}}}{Q_{\mathrm{vw}}}=\frac{\ln \left(R_{\mathrm{e}} / R_{\mathrm{w}}\right)}{\ln \left[\frac{a+\sqrt{a^{2}-(L / 2)^{2}}}{L / 2}\right]+\frac{h}{L} \ln \left(\frac{h}{2 R_{\mathrm{w}}}\right)}$

\section{Flowing ability of thermal wells}

Based on the flow characterization of heavy crude oil in porous media, according to the new productivity models of thermal well, the production statement of thermal wells is investigated. For vertical wells, these parameters are employed. The thickness of oil layer is $6 \mathrm{~m}$, and the permeability in horizontal direction is $3,200 \times 10^{-3} \mu \mathrm{m}^{2}$. The well-distance between injector and producer is $80 \mathrm{~m}$. The wellbore diameter is $0.060 \mathrm{~m}$. We calculate the threshold temperature of heavy oil in vertical wells (open dots) and the certain-productivity temperature of vertical wells (filled dots) at different displacement pressure-drop conditions (the productivity of single vertical well is about $1 \mathrm{~m}^{3} /$ day). The results are listed in Figs. 16, 17 and 18.

The well productivity of thermal horizontal wells could be calculated according to the Eq. (10). For horizontal wells, these parameters are employed. The drainage area of horizontal well is $4.2 \times 10^{4} \mathrm{~m}^{2}$. The horizontal permeability is $3,200 \times 10^{-3} \mu^{2}$. The thickness of oil layer is $10 \mathrm{~m}$. The length of horizontal segment is $180 \mathrm{~m}$. The wellbore diameter of horizontal segment is $0.032 \mathrm{~m}$. The results of the threshold temperature of heavy oil in horizontal wells (open dots) and the certain-productivity temperature of horizontal wells (filled dots) at different displacement pressure-drop conditions (the productivity of 


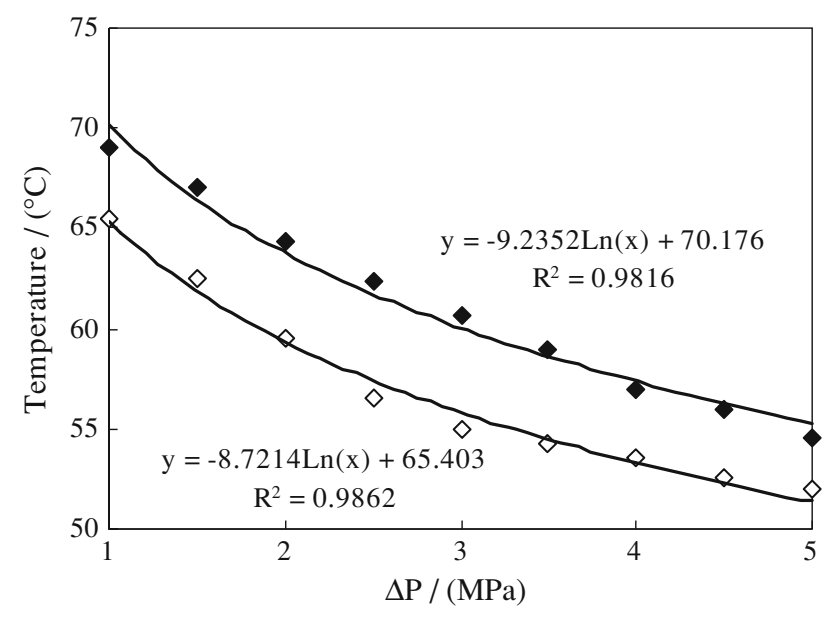

Fig. 16 Relationship curve of temperature and displacement pressure-drop (vertical wells, \#13161)

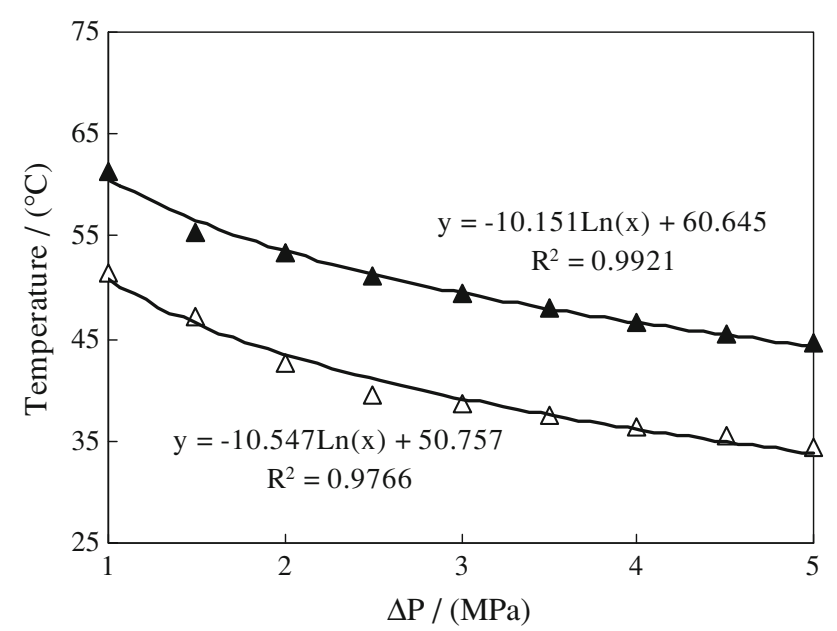

Fig. 17 Relationship curve of temperature and displacement pressure-drop (vertical wells, \#13121)

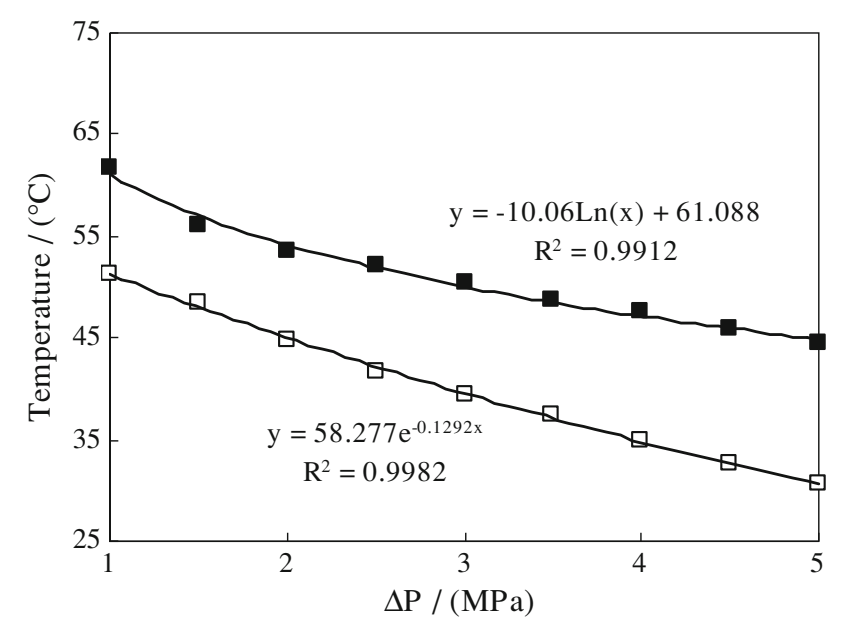

Fig. 18 Relationship curve of temperature and displacement pressure-drop (vertical wells, \#13041) single horizontal well is $10 \mathrm{~m}^{3} /$ day) are listed in Figs. 19, 20 and 21.

As shown, for vertical wells and horizontal wells, with the increase of displacement pressure-drop, the threshold temperature (or the certain-productivity temperature) shows a reducing trend. For the certain productivity temperature, a logarithmic relationship between displacement pressure-drop and temperature could be observed in these three oils. For the heavy crude oil \#13161 and 13121, the threshold temperature also shows a logarithmic relationship with the displacement pressure-drop. However, as the Figs. 18, 19, 20 and 21 shown, for the heavy crude oil \#13041, the threshold temperature and displacement pressure-drop show an exponential relationship.

Besides the influence of reservoir geological properties, the well productivity is mainly related to the oil viscosity and displacement pressure-drop whether for the vertical wells or the horizontal wells. As the Eqs. (5) and (10) shown, a lower oil viscosity and a higher pressure-drop will generate a bigger productivity. From Fig. 11, the viscosity sequence of these three oils at a given temperature is: $\# 13161>\# 13121>\# 13041$. For the relationship of temperature and displacement pressure-drop in vertical wells (Figs. 16, 17, 18), the threshold temperature (or the certainproductivity temperature) of oil \#13161 is the highest among the three oils. The next is the oil \#13121, and oil \#13041 is the lowest. It is significantly related to the flowing characteristics of each one in porous media. Likewise, for the horizontal wells (Figs. 19, 20, 21), the threshold temperature (or the certain-productivity temperature) sequence of these three oils is similar to the vertical wells. From \#13161 to \#13041, the threshold temperature (or the certain-productivity temperature) of thermal wells reduces gradually. Under the same conditions of temperature distribution and displacement pressure-drop, the single-well productivity with a low oil viscosity (\#13041) is the highest.

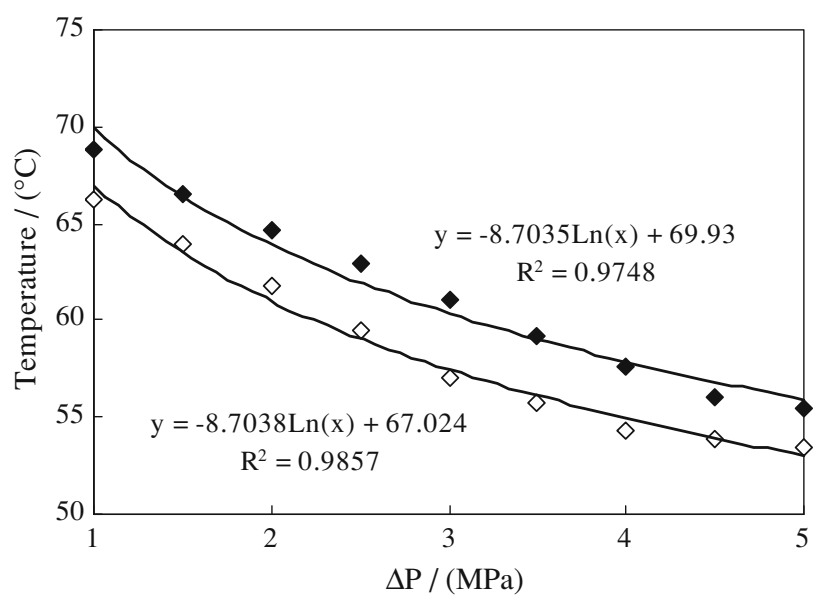

Fig. 19 Relationship curve of temperature and displacement pressure-drop (horizontal wells, \#13161) 


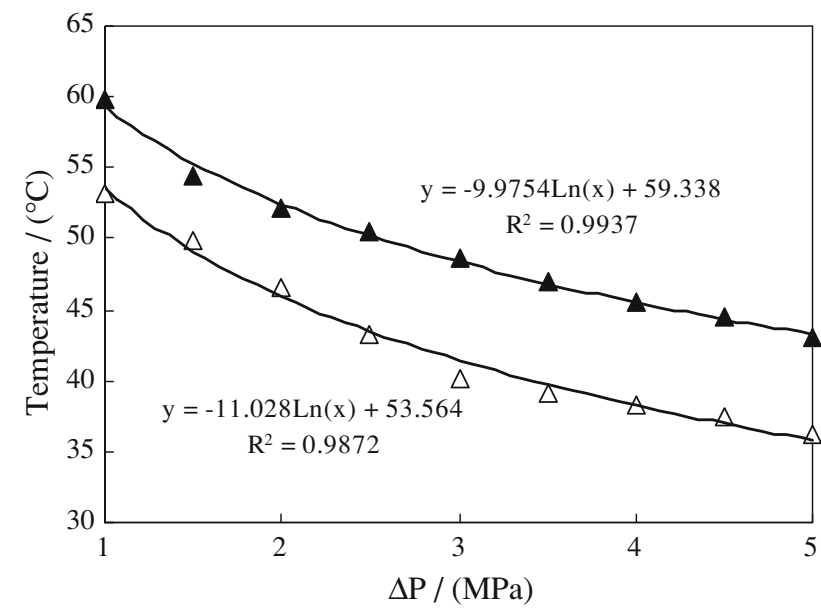

Fig. 20 Relationship curve of temperature and displacement pressure-drop (horizontal wells, \#13121)

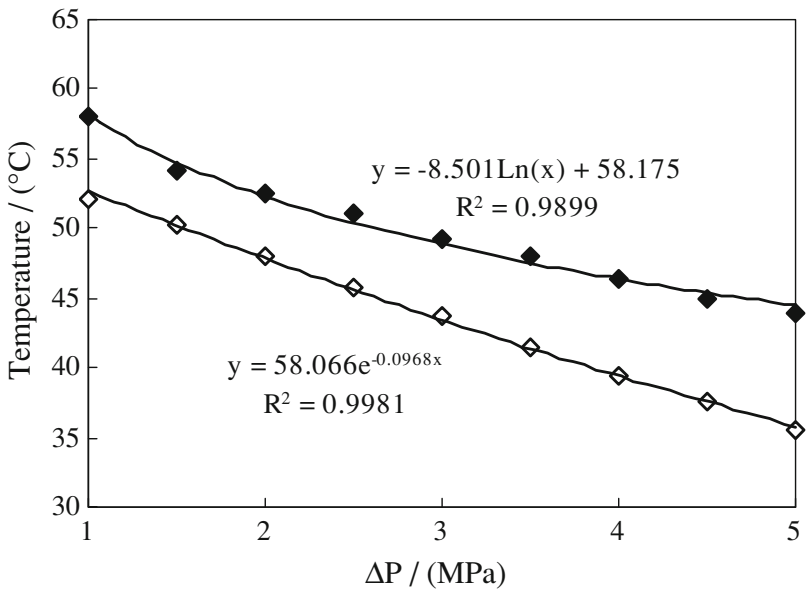

Fig. 21 Relationship curve of temperature and displacement pressure-drop (horizontal wells, \#13041)

In addition, for thermal wells, changing the well-distance between injector and producer or well pattern, we could obtain the single-well productivity at different conditions according to the Eqs. (8) and (13). Besides, from Eq. (14), the productivity differences of different well types at the same reservoir or development conditions could be also obtained. Thus, based on the described reservoir above, the predictive results show the productivity of horizontal well is about 3.09 times than vertical well. The application of thermal horizontal wells tremendously enhanced the oil recovery in heavy oil reservoirs.

\section{Conclusions}

1. Heavy crude oil is a low-temperature non-Newtonian fluid, and there exists a temperature breakpoint of flow-state transformation. The flowing of heavy oil in porous media is closely related with the temperature and pressure gradient, and there exist the TPG and threshold temperature for heavy oil during the flowing process. Heavy crude oil begins to flow only when pressure gradient is in excess of TPG. There dose not exist the TPG above the threshold temperature.

2. The curve of viscosity-temperature for heavy oil is different from the light oil, and it has the obvious property of two straight lines on semilog coordinate. The intersection point of these two lines is defined as the turning point of temperature. It differs from the temperature breakpoint from the flowing experiments of porous media.

3. With the rise of oil viscosity, the TPG of heavy oil is increased gradually. Also the influence of temperature on crude oil with a higher viscosity is more distinct than the low-viscosity oil. There exists a critical temperature. When the temperature is higher than the critical temperature, the reducing trend of TPG with the increase of temperature will slow down. That results from the damage of overlapping phenomena of asphaltenes in crude oil.

4. A new well-productivity model is established, and it considers the influence of TPG and thermal effect of heavy crude oil. It is indicated that the heavy crude oil with a larger oil-viscosity will have a higher threshold temperature (or the certain-productivity temperature) under a given displacement pressure-drop condition. And that heavy crude oil with a higher temperature will also require a low displacement pressure-drop under a given productivity.

5. In comparison with vertical wells, the application of horizontal well enlarges the contact area of wellbore and reservoirs, and it tremendously increases the oil recovery rate. Under the similar condition, the productivity of horizontal wells is about 3.09 times than that of the vertical well.

Acknowledgments This work was financially supported by the National Natural Science Foundation of China (51104165) and the National Science and Technology Major Project of China (2011ZX05009-004-05). The authors also wish to appreciate the Key Laboratory of Petroleum Engineering of the Ministry of Education, China University of Petroleum for the permission to publish this paper.

Open Access This article is distributed under the terms of the Creative Commons Attribution License which permits any use, distribution, and reproduction in any medium, provided the original author(s) and the source are credited.

\section{References}

Alshmakhy A, Maini B (2011) Foaminess and viscosity effects in heavy oil flow. In: Paper CSUG/SPE 145231 presented at the Canadian Unconventional Resources Conference, Calgary

Argillier J-F, Coustet C, Henaut I (2002) Heavy oil rheology as a function of asphaltene and resin content and temperature, SPE. 
In: Paper 79496 presented at the SPE International Thermal Operations and Heavy oil Symposium and International Horizontal Well Technology Conference, Calgary

Chen B, Lu X (1990) Development of heavy and high-viscosity crude oils, chap. 3. Petroleum Industry Press, Beijing (in Chinese)

Chen M, Rossen W, Yortsos YC (2005) The flow and displacement in porous media of fluids with yield stress. Chem Eng Sci 60:4183-4202

Christos DT (2004) Correlation of the two-phase flow coefficients of porous media with the rheology of shear-thinning fluids. J NonNewtonian Fluid Mech 117:1-23

Govier GW, Fogurasi M (1972) The interpretation of data on the rheological behavior of thixotropic crude oils. J Can Pet Tech 11:42-53

Henaut I, Argillier J-F, Pierre C, Moan M (2003) Thermal flow properties of heavy oils. In: Paper OTC 15278 presented at the Offshore Technology Conference, Houston

Joshi SD (1988) Augmentation of well productivity with slant and horizontal wells. J Pet Tech 40:729-739

Ovalles C, Rogel E, Segerstrom J (2011) Improvement of flow properties of heavy oils using asphaltene modifiers. In: Paper SPE 146775 presented at the SPE Annual Technical conference and Exhibition, Denver

Owayed JF, Tiab D (2008) Transient pressure behavior of Bingham non-Newtonian fluids for horizontal wells. J Pet Sci Eng 61:21-32

Prada A, Civan F (1999) Modification of Darcy's law for the threshold pressure gradient. J Pet Sci Eng 22:237-240
Pruess JY, Zhang S (1990) The rheological properties of heavy oils. Oil Gas Storage Transp 8:34-39

Rojas MA, Castagna J, Krishnamoorti R, Han D-h, Tutuncu A (2008) Shear thinning behavior of heavy oil samples: laboratory measurements and modeling. In: Paper 2008-1714 presented at the SEG Annual Meeting, Las Vegas

Schramm LL, Kwak JCT (1988) The rheological properties of an Athabasca bitumen and some bituminous mixtures and dispersions. J Can Pet Tech 27:1-11

Song F-q, Liu C-q, Wu B-z (2001) The fast transient measurement of threshold pressure gradient. Acta Petrolei Sinica 22:67-70 (in Chinese)

Steinborn R, Flock DL (1983) The rheology of heavy crude oils and their emulations. J Can Pet Tech 22:37-52

Thomas LK, Katz DL, Tek MR (1967) Threshold pressure phenomena in porous media. SPE $\mathrm{J}$ 8:174-184

Wang S, Huang Y, Civan F (2006) Experimental and theoretical investigation of the Zaoyuan field heavy oil flow through porous media. J Pet Sci Eng 50:83-101

Wu YS, Pruess K (1998) A numerical method for simulating nonNewtonian fluid flow and displacement in porous media. Adv Water Resour 21:351-362

Wu Y-S, Pruess K, Witherspoon PA (1992) Flow and displacement of Bingham non-Newtonian fluids in porous media. SPE Res Eng 7:369-376

Yang W-x, He S-1 (2003) Experimental investigation on rheological characteristics of oils under different measuring conditions. J Uni Pet China 27:39-41 (in Chinese) 